\title{
Lesbian and bisexual women's likelihood of becoming pregnant: a systematic review and meta-analysis
}

\author{
K Hodson, ${ }^{a}$ C Meads, ${ }^{b}$ S Bewley \\ ${ }^{a}$ Queen's Hospital, Romford, Essex, UK ${ }^{\mathrm{b}}$ Department of Health, Social Care and Education, Anglia Ruskin University, Cambridge, UK \\ c Division of Women's Health, Women's Health Academic Centre, King's College London and King's Health Partners, St Thomas' Hospital \\ Campus, London, UK \\ Correspondence: S Bewley, Division of Women's Health, Women's Health Academic Centre, King's College London and King's Health \\ Partners, $10^{\text {th }}$ Floor North Wing, St Thomas' Hospital Campus, London SE1 7EH, UK. Email susan.bewley@kcl.ac.uk
}

Accepted 28 September 2016. Published Online 15 December 2016.

This article includes Author Insights, a video abstract available at https://vimeo.com/rcog/authorinsights14414.

Background Few data exist regarding pregnancy in lesbian and bisexual (LB) women.

Objectives To determine the likelihood of LB women becoming pregnant, naturally or assisted, in comparison with heterosexual women

Search strategy Systematic review of papers published 1 January 2000 to 23 June 2015.

Selection criteria Studies contained details of pregnancy rates among LB women compared with heterosexual women. No restriction on study design.

Data collection and analysis Inclusion decisions, data extraction and quality assessment were conducted in duplicate. Meta-analyses were carried out, with subgroups as appropriate.

Main results Of 6859 papers identified, 104 full-text articles were requested, 30 papers (28 studies) were included. The odds ratio (OR) of ever being pregnant was 0.19 (95\% CI 0.18-0.21) in lesbian women and 1.22 (95\% CI 1.15-1.29) in bisexual women compared with heterosexual women. In the general population, the odds ratio for pregnancy was nine-fold lower among lesbian women and over two-fold lower among bisexual women $(0.12$ [95\% CI 0.12-0.13] and 0.50 [95\% CI 0.45-0.55], respectively). Odds ratios for pregnancy were higher for both LB adolescents (1.37 [95\% CI 1.18 1.59 ] and 1.98 [95\% CI 1.85, 2.13], respectively). There were inconsistent results regarding abortion rates. Lower rates of previous pregnancies were found in lesbian women undergoing artificial insemination (OR 0.17 [95\% CI 0.11-0.26]) but there were higher assisted reproduction success rates compared with heterosexual women (OR 1.56 [95\% CI 1.24-1.96]).

Conclusions Heterosexuality must not be assumed in adolescents, as LB adolescents are at greater risk of unwanted pregnancies and terminations. Clinicians should provide appropriate information to all women, without assumptions about LB patients' desire for, or rejection of, fertility and childbearing.

Keywords Artificial insemination, bisexual, lesbian, pregnancy, systematic review.

Tweetable abstract Review of likelihood of LB women becoming pregnant: LB teenagers at greater risk of unwanted pregnancies.

Linked article This article is commented on by MJ Eliason, p. 403 in this issue. To view this mini commentary visit http:// dx.doi.org/10.1111/1471-0528.14488.

Please cite this paper as: Hodson K, Meads C, Bewley S. Lesbian and bisexual women's likelihood of becoming pregnant: a systematic review and metaanalysis. BJOG 2017;124:393-402.

\section{Introduction}

Lesbian motherhood has been called 'a contradiction in terms', ' with an assumed lack of desire among lesbian women to be mothers. Women may be considered lesbian

Review registration number Prospero CRD42014007594 or bisexual through self-identification, or choice of sexual partner(s). Many are fertile, and some desire children. ${ }^{2}$

Worldwide, civil rights and legal discrimination towards lesbian and bisexual (LB) women vary; policies range from the death penalty ${ }^{3}$ to full adoption, family and fertility rights. ${ }^{3,4}$ Since the millennium, more countries have legalised same-sex marriage. , $^{5}$ 
Routes to LB parenting include previous heterosexual relationships, planned nonbiological same-sex parenting, sexual intercourse, insemination, adoption, fostering and surrogacy. Markets in assisted reproduction and surrogacy have dissociated genetic parenting from social parenting further than traditional practices of non-paternity and adoption.

Same-sex families are increasingly recognised and normalised within the media, ${ }^{7}$ adoption and fertility policies. ${ }^{8-10}$ Access to information and support groups is widely available. ${ }^{1-14}$ Groundbreaking reports of reassuring outcomes for children $^{15,16}$ influenced social acceptability. Previously, concealing sexuality to avoid traumatic legal separation of mothers from their children had been common in the 1980s. ${ }^{17}$ Alongside dramatic social change, the numbers of women engaging in LB behaviour may be increasing, ${ }^{18}$ though evidence remains of prejudice, ${ }^{19}$ stigma $^{20}$ and bullying of young lesbian women, ${ }^{21,22}$ with impacts on mental health. ${ }^{23,24}$

The UK National Institute for Health and Care Excellence equity recommendations include issues about artificial insemination in lesbians. Six self-funded attempts at conception are required before entitlement to NHS funding -heterosexual women do not face this financial impediment. ${ }^{12}$ The American Congress of Obstetricians and Gynecologists have endorsed same-sex marriage equality, ${ }^{25}$ but give no specific guidance regarding fertility. The UK Royal College of Obstetricians and Gynaecologists have not commented on lesbians, their website only linking to a Human Fertilisation and Embryo Bill parliamentary briefing. The International Federation of Gynecology and Obstetrics website links only to irrelevant documents. Both the European Society of Human Reproduction and Embryology and the European Society of Gynaecology websites are uninformative for anyone seeking guidance.

Alongside new notions about the status of non-parents (i.e. chosen or 'child-free', versus involuntary or 'childless'), same-sex parenting is becoming established within the public consciousness. Less is known about the prevalence of pregnancy among adolescents and adults, success of assisted reproduction, comparative fecundity of heterosexual and LB women and how factors such as sexuality and access to sperm affect fecundity. Pregnancy rates among LB and heterosexual women are important for baseline reference data in the context of artificial insemination. Our knowledge of LB pregnancy therefore needs updating.

\section{Methods}

This systematic review examines the association between LB women's identity or behaviour and their likelihood of becoming pregnant, whether intentionally or accidentally, or being mothers compared with heterosexual women. It was conducted according to a prespecified protocol lodged with PROSPERO (CRD42014007594) on 17 February 2014.

\section{Inclusion criteria}

Studies were eligible using the following inclusion criteria: (1) Population-women self-described as lesbian or bisexual, women who described themselves as having sex with women, or having sex with women and men; (2) Exposure -women exploring any interest or desire for pregnancy, or attempting to become pregnant; (3) Comparator-heterosexual women or women self-describing as only having sex with men; (4) Study Design - any comparative studies including randomised controlled trials or other experimental studies, cohort studies, case-control studies or cross-sectional surveys. Studies had to contain primary data and be peer-reviewed. Only studies reporting after the year 2000 were eligible. There was no restriction on setting or language. Studies were excluded if the sexual orientation and behaviour of women were not clear, if there was no comparison with heterosexual women or if they were opinions, editorials, conference abstracts or case reports.

\section{Search strategy}

Search terms were developed based on the population and exposures sought. MeSH terms and synonyms were used to widen the search. A total of six databases were used: Ovid Medline; Ovid Embase; Ovid PsycInfo; Web of ScienceScience Citation Index; Cochrane Central; British Nursing Index. Searches were limited to 1 January 2000 to 23 June 2015. Reference lists of reviews and primary studies were also searched. The authors checked studies on lesbian health used in other projects. A full table of search terms can be found in the Table S1.

\section{Study selection}

After removing duplicates, the remaining papers were assessed independently for relevance first by title $(\mathrm{KH}$, $\mathrm{CM})$, and then by abstract ( $\mathrm{KH}, \mathrm{CM}, \mathrm{SB})$. All articles were included for full-text assessment if any author considered the abstract relevant or there was uncertainty. Full-text assessment to determine inclusion in the systematic review was carried out by all authors together. Any disagreements were resolved by discussion.

\section{Data extraction and analysis}

A standard form was devised before data extraction and quality scoring, based on the content of the papers and the aims of the review, including funding sources and following piloting. Outcome variables were any kind of pregnancy reported. Numbers of participants and outcomes of interest were reported in each group where available. Percentages were converted to numbers where necessary, using backcalculation and estimates from figures in the published articles when required. Data were independently extracted by two authors $(\mathrm{KH}$ and $\mathrm{CM})$ and discrepancies were resolved 
through discussion. Fourteen authors were contacted about unobtainable publications, data discrepancies and/or other enquiries and most replied.

\section{Quality assessments}

Studies were appraised for selection, performance, attrition and detection biases and whether the study would be representative of LB women in the general population. As there were different study designs, no formal quality appraisal checklist was used. Risk of bias was assessed during tabulation of study characteristics and used to interpret study results.

\section{Data synthesis and meta-analysis}

Results were tabulated separately for population samples (no assisted reproduction mentioned), previous pregnancies in artificial insemination samples and results of assisted reproduction, distinguishing between method (intracervical insemination, ICI; intrauterine insemination, IUI; in vitro fertilisation, IVF). Meta-analysis was conducted using REVMAN version 5.3 (Copenhagen: the Nordic Cochrane Centre, the Cochrane Collaboration 2014) on the outcome of ever being pregnant, in LB women, in population samples and assisted reproduction samples separately. Subgroup analysis of success rates in women undergoing assisted reproduction, based on method, was conducted. Due to the heterogeneity of studies, subgroup analysis by study-type was also conducted. There were no prespecified additional analyses, but subgroups of adolescent and general populations in LB women were examined separately for the summary measures of the odds ratio of ever being pregnant in population samples. Random effects models were used due to heterogeneity of study samples and study designs. Heterogeneity was assessed through the $I^{2}$ statistic, using standard cut-offs. Meta-regression was not used because of the lack of appropriate data. No formal measures were used to assess publication bias. Results focused on pregnancies and biological children per woman. When reporting average numbers of children per couple or family, numbers may be influenced by a split across two women in a same-sex couple, rather than a man and a woman.

\section{Results}

From 6859 records (1705 duplicates), 104 citations were selected for evaluation, of which two papers were unavailable and 102 full papers were read (KH, CM). Twenty-eight studies (30 papers) were included (see Table S3). The Supplementary material also shows the numbers of citations at each stage of the review (Figure S1; PRISMA flow chart) and lists the excluded studies with reasons for exclusion (Table S2).

\section{Study characteristics}

The 28 studies had a variety of different populations, exposures, study designs, settings and outcomes (see Table S3). All included studies came from high-income countries (13 USA, four UK, three Sweden, two Australia, and one each Belgium, Canada, Denmark, France, the Netherlands and Norway). No primary study was found that directly addressed the original research question. There were five prospective cohort studies, seven retrospective cohort studies, five case-control studies and 11 cross-sectional surveys. Settings varied and included nurse surveys, health centres, infertility clinics, general public and schools. For those studies that looked at assisted reproduction, methods varied between artificial insemination and in vitro fertilisation, and were recorded as specified in each paper; details can be found in Table S3. Sizes ranged from $89^{26}$ to $148009^{27}$ participants. Recruitment methods varied and included snowball, clinic and school samples, as well as population samples. Five studies specifically included adolescent samples only. ${ }^{27-31}$ Aside from these samples, ages ranged from 16 to $>60$ years. White/Caucasian women were the majority group in all papers in which ethnicity was documented. Data collection included researcher interviews, self-completed and medical-staff-completed questionnaires, computer-assisted self-administered questionnaires and medical chart review. Sexual orientation, identity or behaviour was ascertained through self-report questionnaires, and LB identity or behaviour was likely to have been under-estimated, particularly in population samples. Funding sources were wide ranging, although 11 had no details of funding or were unfunded. With regards to potential bias, of those studies providing funding details, one was supported by a fertility laboratory, ${ }^{32}$ and another by a pharmaceutical company. ${ }^{33}$ Four studies were supported by organisations in support of sexual minority rights.

\section{Findings}

Table S4 shows pregnancy outcomes in the population surveys. All studies showed measurable pregnancy rates in lesbians, ranging from 9.9\% (previous births in women who exclusively have sex with women) ${ }^{34}$ to $37 \%$ (ever pregnant in lesbians). ${ }^{35}$ Adult studies or those with a wide range of population ages showed lower rates of pregnancies (all outcomes) in LB women compared with heterosexual women. All five adolescent studies showed higher rates of pregnancies in LB girls compared with heterosexual girls. Figures 1 and 2 explore this further in lesbian and bisexual women separately. Figure 1 shows that the rate of pregnancy was significantly higher in teenage samples of lesbians compared with their heterosexual peers, whereas in whole population samples the reverse was true. This is reiterated in 
Hodson et al.

the Figure S3, with results seen in Figure S1 sub-grouped by study design. Figure S4 (see Supplementary material) shows a higher rate of pregnancy in heterosexual women than lesbian women, when studies concerning adolescents are removed from the meta-analysis. This trend can also be seen for bisexual teens and bisexual women of all age groups.

Seven studies reporting induced abortion showed mixed results. There were lower rates in LB women than heterosexual women in four studies, ${ }^{35-38}$ and higher rates in three studies, ${ }^{31,34,39}$ but the only study in adolescents (small sample sizes, bisexuals only) reported higher rates of unwanted pregnancy and termination. ${ }^{31}$

Table 1 and Figure S2 (see Supplementary material) report previous pregnancy experiences in women undergoing artificial insemination and show fewer pregnancy attempts and fewer previous pregnancies in lesbians (no bisexual data).

Table 2 reports pregnancy rates in the artificial insemination studies (an unabridged version of this table is given in the Table S5). This showed that pregnancy rates were similar or higher in lesbian than heterosexual women (no bisexual data available). Subgroup analysis of method of assisted reproduction reiterated this (see Figure S5).

Meta-analysis showed that there was a higher rate of pregnancy in samples of lesbians (Figure 1) and bisexual adolescents (Figure 2) compared with heterosexual adolescents, whereas the general population samples showed a lower rate in lesbian (Figure 1) and bisexual (Figure 2) women compared with heterosexual women. The odds ratio of ever being pregnant was 0.19 (95\% CI $0.18-0.21$ ) in lesbian women and 1.22 (95\% CI 1.15-1.29) in bisexual women compared with heterosexual women. In the general population, the odds ratio for pregnancy was nine-fold lower among lesbian women and over two-fold lower among bisexual women $(0.12$ [95\% CI $0.12-0.13]$ and 0.50 [95\% CI 0.45-0.55], respectively) compared with heterosexual women. Conversely, the odds ratios for pregnancy were higher for both lesbian adolescents and bisexual adolescents (1.37 [95\% CI 1.18-1.59] and 1.98 [95\%

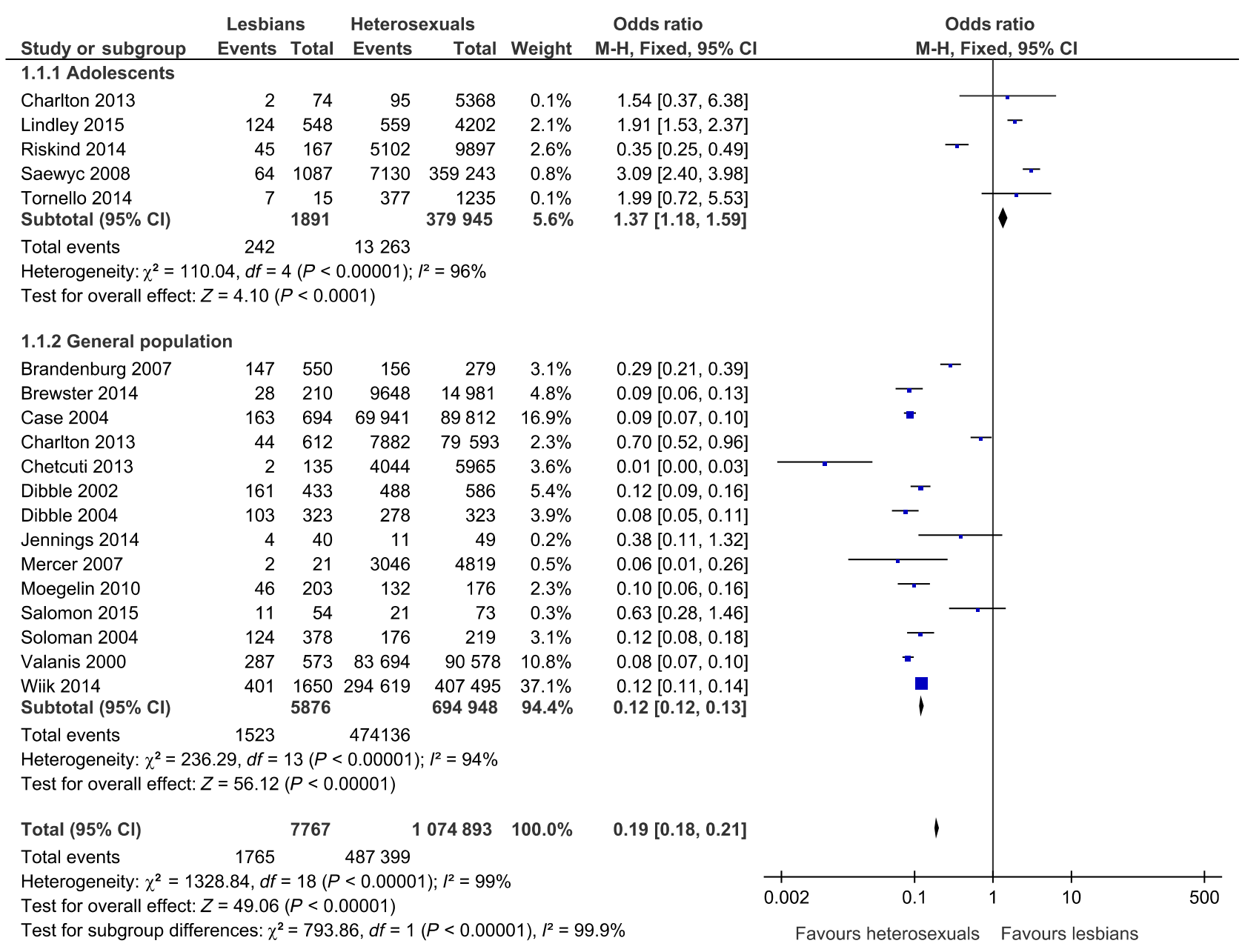

Figure 1. Meta-analysis of ever being pregnant in lesbian women compared with heterosexual women. 


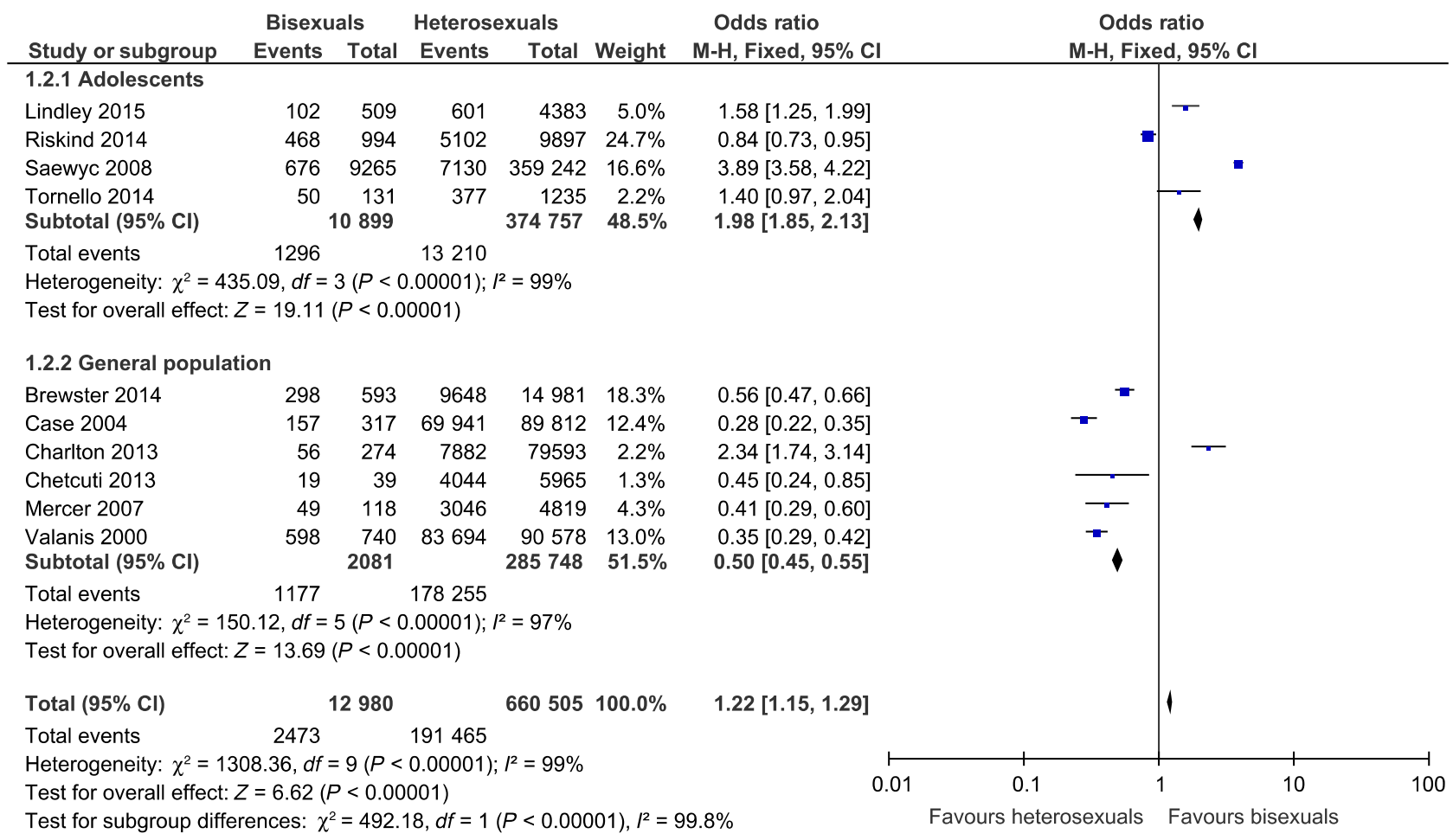

Figure 2. Meta-analysis of ever being pregnant in bisexual women compared with heterosexual women.

Table 1. Artificial insemination samples: previous pregnancies

\begin{tabular}{|c|c|c|c|c|}
\hline \multirow[t]{2}{*}{ Author (Year) } & \multirow[t]{2}{*}{ Outcome measure } & \multicolumn{3}{|c|}{ Quantitative results } \\
\hline & & Lesbian \% $(n / N)$ & Comparison group \% $(n / N)$ & Statistics \\
\hline $\begin{array}{l}\text { Agrawal et al. } \\
(2004)^{32}\end{array}$ & Ever attempted to get pregnant & $5.2 \%(13 / 254)$ & $\begin{array}{l}\text { Single heterosexual women } \\
29.5 \%(40 / 136) \\
\text { Heterosexual in a } \\
\text { relationship 97.8\% (223/228) }\end{array}$ & No test reported \\
\hline $\begin{array}{l}\text { Borneskog et al. } \\
(2012)^{47}\end{array}$ & $\begin{array}{l}\text { Previous biological children } \\
\text { Adoptive children } \\
\text { Stepchildren }\end{array}$ & $\begin{array}{c}3 \%(5 / 166) \\
3.6 \%(6 / 166) \\
9 \%(15 / 166)\end{array}$ & $\begin{array}{c}11.3 \%(17 / 151) \\
0.7 \%(1 / 151) \\
2 \%(3 / 151)\end{array}$ & $\begin{array}{l}\text { NS } \\
\text { NS } \\
\text { NS }\end{array}$ \\
\hline $\begin{array}{l}\text { Ferrara et al. } \\
(2000)^{55}\end{array}$ & $\begin{array}{l}\text { Previous pregnancy } \\
\text { Previous live birth } \\
\text { Previous termination of pregnancy } \\
\text { Previous miscarriage } \\
\text { Previous IUI-DI pregnancy } \\
\text { Previous IUI-DI live birth }\end{array}$ & $\begin{array}{r}11 \%(4 / 35) \\
3 \%(1 / 35) \\
9 \%(3 / 35) \\
0 \%(0 / 35) \\
6 \%(2 / 35) \\
3 \%(1 / 35)\end{array}$ & $\begin{array}{l}43 \%(52 / 122) \\
11 \%(13 / 122) \\
25 \%(31 / 122) \\
7 \%(8 / 122) \\
7 \%(9 / 122) \\
4 \%(5 / 122)\end{array}$ & $\begin{array}{l}P<0.001 \\
\text { NS } \\
\text { NS } \\
\text { NS } \\
\text { NS } \\
\text { NS }\end{array}$ \\
\hline $\begin{array}{l}\text { Nordqvist et al. } \\
(2014)^{58}\end{array}$ & $\begin{array}{l}\text { Previous total pregnancies } \\
\text { Previous abortions } \\
\text { Previous miscarriage } \\
\text { Previous extrauterine pregnancy } \\
\text { Previous children }\end{array}$ & $\begin{array}{c}24.5 \%(38 / 155) \\
18.1 \%(28 / 155) \\
9.0 \%(14 / 155) \\
0.6 \%(1 / 155) \\
2.6 \%(4 / 155)\end{array}$ & $\begin{array}{c}30.7 \%(35 / 114) \\
15.8 \%(18 / 114) \\
8.8 \%(10 / 114) \\
0.9 \%(1 / 114) \\
11.4 \%(13 / 114)\end{array}$ & $\begin{array}{l}P=0.26 \\
P=0.64 \\
P=1.00 \\
P=1.00 \\
P=0.003\end{array}$ \\
\hline
\end{tabular}

Key: IUI-DI, intrauterine donor insemination.

CI 1.85-2.13], respectively). There were inconsistent results regarding rates of induced abortions. Lower rates of previous pregnancies were found in lesbians undergoing artificial insemination (OR $0.17 ; 95 \%$ CI $0.11-0.26)$ but there were higher assisted reproduction success rates in lesbians compared with heterosexual 


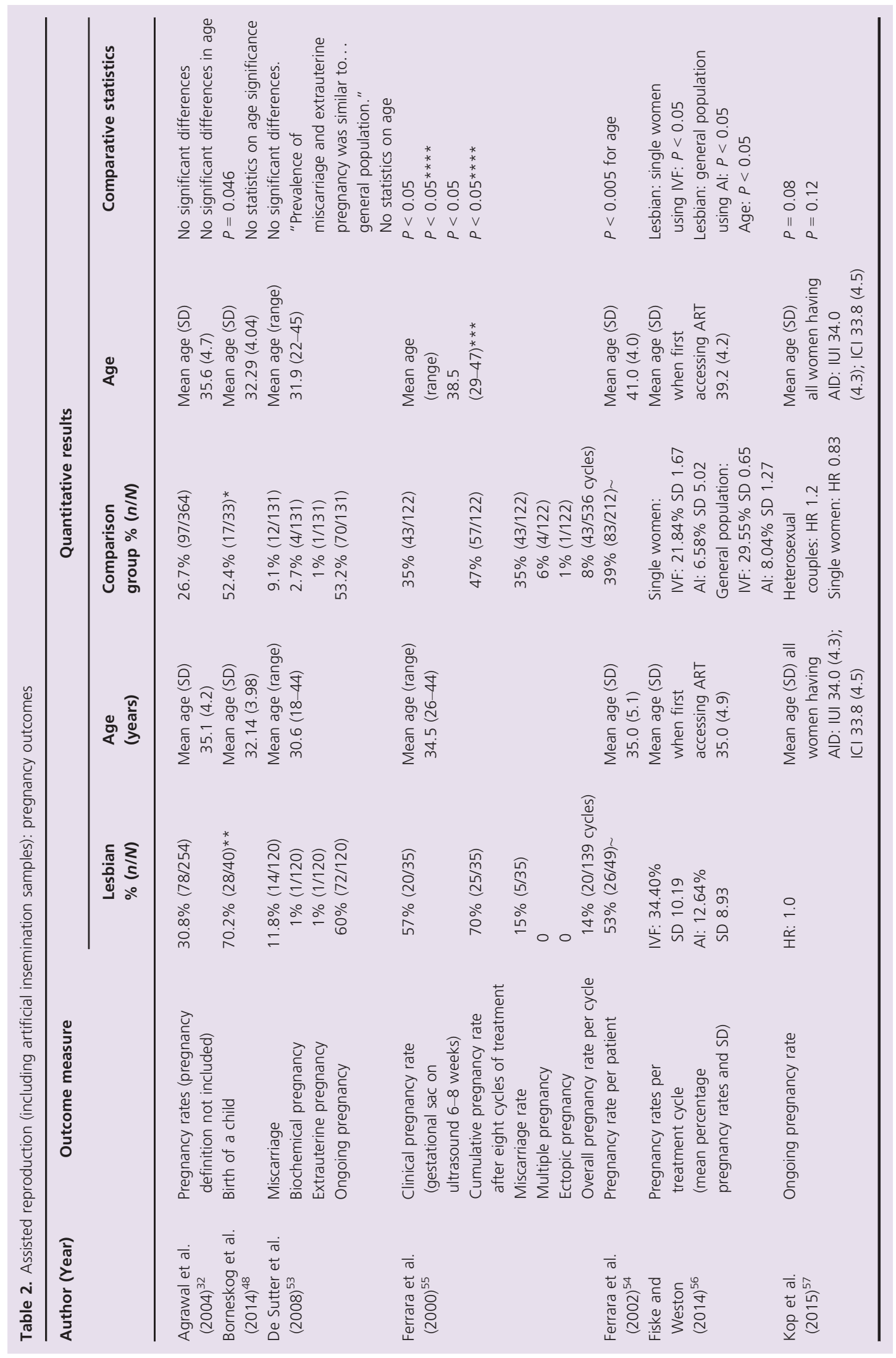




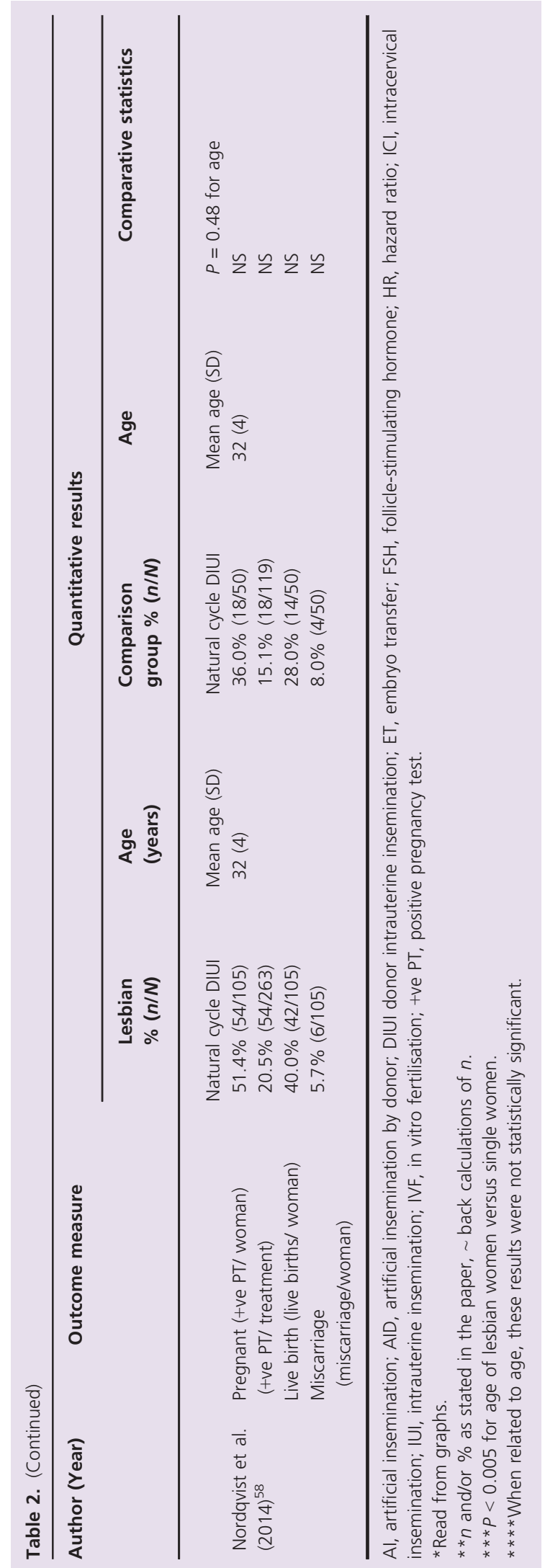

women (OR 1.56; 95\% CI 1.24-1.96). It was not possible to analyse pregnancy outcomes with respect to age and other fertility factors due to lack of data.

\section{Discussion}

\section{Main findings}

This systematic review found no primary research on pregnancy in LB women compared with heterosexual women. Nevertheless, there was much secondary data available to show that lesbian or bisexual sexual orientation does not equate to a desire for, nor rejection of, fertility and childbearing. Most studies showed lower rates of pregnancies (all outcomes) in LB women, although rates were higher in adolescents. In terms of previous pregnancy experiences, it showed fewer pregnancy attempts and fewer previous pregnancies. Pregnancy success rates in lesbian women undergoing artificial insemination tended to be higher.

\section{Strengths and limitations}

The strengths of this review include protocol preregistration in the PROSPERO database and careful design of the presentation of numerical results. Despite searching for studies irrespective of publication language, no foreign language papers were found. Recognising that identity is not the same as behaviour, and may be fluid over a lifetime, the systematic review reported all definitions. It was surprising how many papers included statistics on pregnancy in LB women although pregnancy statistics were not the primary focus. Instead, they were looking at topics such as polycystic ovarian disorders or breast cancer modelling, and pregnancy rates were found only by searching the full paper. Therefore there may be other publications not found by the search strategy that might yield further useful information. However, there is sufficient consistent information to draw some clinical conclusions with generalisability. Limitations include a lack of formal quality assessment of included studies. This proved difficult due to the fact that no two papers were alike and that there are no validated quality checklists for prevalence, the main focus of interest. It was impossible to look at confounders such as ethnicity, social class, education, body mass index, medical conditions or actual sexual behaviours (i.e. 'lifetime' lesbians versus those with some previous heterosexual experience) due to lack of details within the published papers.

\section{Interpretation}

We found one previous systematic review of donor insemination and assisted reproduction in lesbian women and gay men. ${ }^{40}$ This reported only a subset of the eligible papers we found, using only one database in the search strategy and without a formal statement of inclusion criteria. It 
concluded that lesbians tended to have higher pregnancy rates than the heterosexual comparators in the studies that they had found, but there were sampling biases and small sample sizes that hampered interpretation. A previous systematic review on lesbian experiences and needs during childbirth $^{41}$ narratively evaluated several topics including disclosure of sexual orientation to healthcare providers and options for conception of a child in lesbians. There have been no previous systematic reviews of pregnancy and artificial insemination rates in LB women.

As LB women's sexual orientation does not equate to a desire for, nor rejection of, fertility and childbearing, clinicians should provide appropriate information to all women. They must not make assumptions about the existence, or overlapping, of sexuality, fertility and desire for children in any of their female patients in any sexual health, reproductive, fertility, obstetric or gynaecological settings. In particular, heterosexuality should not be assumed in young peoples' sexual and reproductive health services as, if anything, there are greater risks of unwanted pregnancy at this time, and much higher rates of forced sex have also been reported. ${ }^{31}$ Given these risks, LB adolescents may also be at increased risk of sexually transmitted infections that can impact future fertility; this should be investigated further. It is unclear why we found higher rates of pregnancy in LB adolescent women, and further research might help, but LB adolescents may need considerable help with advice, support for emergent sexuality, contraception and safe abortion because of the higher risks of teenage pregnancy. These issues apply no matter whether the clinical setting is a miscarriage unit, antenatal clinic or genitourinary clinic. In an ideal world, every mother would be willing, every child wanted, and all women would be able to choose whether they wanted to be a mother or not irrespective of access to sperm.

Lesbian and bisexual women have 'social' rather than medical infertility, so it is unsurprising that pregnancy rates are higher after artificial insemination, although few studies were corrected for age. It is important for obstetricians and gynaecologists to be aware of developments in the marketplace in LB women's assisted reproduction, which may impact their patients. For example, a new model of pregnancy (i.e. intra-couple surrogacy) is being offered to fertile females within a same-sex couple (including discounted cycles in return for egg donation to infertile couples). There is potential for exploitation of vulnerable women (e.g. by claiming egg donation is a 'true genetic exchange' $)^{42}$ and significantly increased risks of pre-eclampsia have been reported for egg recipients. ${ }^{43}$ On the one hand, LB women may prefer the control, anonymity and some consumer protection with medically assisted artificial insemination. On the other, there are financial disadvantages compared to 'do-ityourself informal arrangements with fresh, rather than frozen, semen. Clinicians should be able to discuss the pros and cons of all forms of pregnancy and be able to direct LB women to sources of help. LB women should be informed that, with artificial insemination, their chances of pregnancy are good.

Healthcare professionals should be mindful that a sizeable proportion of lesbians are, or wish to be, mothers, and maternity staff should be aware that not all of their patients are heterosexual. Research has suggested that a relatively large proportion of general practitioners have difficulties with discussing sexual identity with their patients. ${ }^{44,45}$ If this is still the case, work needs to be done to help some practitioners be more confident and comfortable with their LB patients. This may also be true with maternity staff. ${ }^{46}$ How best to achieve this at the moment is unclear, and studies exploring methods of training health staff should be developed.

\section{Conclusion}

The research available is sufficient to demonstrate that a sizeable proportion of LB women have pregnancies and children. It is currently unclear as to why there is a higher rate of pregnancies in teenage LB women than their heterosexual peers and the reasons need to be established. Similarly, it remains to be explored whether the difference in adult general population rates are due to a lack of desire for pregnancy, demand, historical and cultural social norms, or inherent differences in LB women. Higher rates of pregnancy in LB adolescents might follow their being more adventurous or sexually active in general, more forced or unplanned sex without contraception, or if they experiment with heterosexuality to persuade themselves that they are heterosexual. There was insufficient information on the rates of unwanted pregnancies, induced abortions or terminations to know whether adolescent LB women are contributing unexpectedly larger proportions to adolescent termination of pregnancy statistics. The multitude of possible explanations needs to be teased out to help and support them and also to prevent unwanted teenage pregnancies in this group. More primary research is required on LB women's pregnancy needs and outcomes, particularly exploring the context and impact of assisted reproductive technologies.

\section{Disclosure of interests}

None declared. Completed disclosure of interests form available to view online as supporting information.

\section{Contribution to authorship}

The authors were involved as follows: KH, CM, SB conception, design, execution, analysis, drafting manuscript and critical discussion; all were responsible for revision and final approval of the manuscript. All authors had full access to all of the data (including statistical reports and tables) in the study and can take responsibility for the integrity of 
the data and the accuracy of the data analysis. Susan Bewley is the guarantor for the study.

\section{Details of ethics approval}

Not required.

\section{Funding}

The study arose from an initial student project undertaken during a part-funded BSc at King's College London $(\mathrm{KH})$ but was otherwise unfunded.

\section{Acknowledgements}

We thank the librarians at Kings College London for help with initial search terms. Open access for this article was funded by King's College London.

\section{Supporting Information}

Additional Supporting Information may be found in the online version of this article:

Figure S1. PRISMA flow chart.

Figure S2. Meta-analysis of previous pregnancies in lesbian women compared with heterosexual women all undergoing artificial insemination.

Figure S3. Meta-analysis of ever being pregnant in lesbian women compared with heterosexual women, subgrouped by study design.

Figure S4. Meta-analysis of ever being pregnant in lesbian women compared with heterosexual women, subgrouped by study design, and with those studies concerning adolescents removed.

Figure S5. Meta-analysis of assisted reproduction success rates in lesbian women compared with heterosexual women.

Table S1. Search strategy.

Table S2. Unobtainable and excluded studies with reasons.

Table S3. Characteristics of the included studies.

Table S4. Population samples: pregnancy outcomes.

Table S5. Assisted reproduction (including artificial insemination samples): pregnancy outcomes (unabridged).

Video S1. Author Insights.

\section{References}

1 Lewin E. Looking for Lesbian Motherhood. Lesbian Mothers: Accounts of Gender in American Culture. New York: Cornell University Press, 1993.

2 Chabot JM, Ames BD. "It wasn't, 'Let's get pregnant and go do it':" Decision making in lesbian couples planning motherhood via donor insemination. Fam Relat 2004;53:348-56.

3 Carroll A, Paoli LP. A World Survey of Laws: Criminalisation, Protection and Recognition of Same-Sex Love. 2015. [http://old. ilga.org/Statehomophobia/ILGA_State_Sponsored_Homophobia_2015. pdf]. Accessed 12 January 2016.

4 Business Insider. 13 Countries that are More Gay-Friendly than America. 2013. [www.businessinsider.com/worlds-most-gay-friendlycountries-2013-3?op=1\&IR=T]. Accessed 17 April 2016.
5 The Guardian. Ireland Becomes First Country to Legalise Gay Marriage by Popular Vote. 2015. [www.theguardian.com/world/2015/may/ 23/gay-marriage-ireland-yes-vote]. Accessed 12 January 2016.

6 New York Times. Supreme Court Ruling Makes Same-Sex Marriage a Right Nationwide. 2015. [www.nytimes.com/2015/06/27/us/supremecourt-same-sex-marriage.html?_r = 0]. Accessed 12 January 2016.

7 Bologna C. Lesbian Couple's Side-by-Side Pregnancy Photos are Truly Aww-Worthy. Huffington Post. 2015. [www.huffingtonpost.com/2015/ 04/21/lesbian-couple-pregnancy-photos_n_7103776.html]. Accessed 12 January 2016.

8 NICE. Fertility: assessment and treatment for people with fertility problems. 2013. [www.nice.org.uk/guidance/cg156/evidence]. Accessed 12 January 2016.

9 Family Equality Council. Joint Adoption Laws, 2015. [www. familyequality.org/get_informed/equality_maps/joint_adoption_laws/]. Accessed 12 January 2016.

10 Seligman F. Casal Homossexual Pode Adotar Criança, Decide STJ (Brazilian). AthosGLS, 2010. [www.athosgls.com.br/noticias_visualiza. php?contcod=29208]. Accessed 12 January 2016.

11 Stonewall UK. Pregnant Pause: A Guide for Lesbians on how to get Pregnant. 2009. [www.stonewall.org.uk/resources/pregnant-pauseguide-lesbians-how-get-pregnant]. Accessed 12 January 2016.

12 NHS Choices. New NICE guidelines for NHS fertility treatment. 2013. [www.nhs.uk/news/2013/02February/Pages/New-NICE-guidelines-forNHS-fertility-treatment.aspx]. Accessed 12 January 2016.

13 IVF Australia. Options for same-sex couples. 2015. [http://ivf.com.au/ fertility-treatment/same-sex-couple-options]. Accessed 12 January 2016.

14 USC (University of Southern California) Fertility. Gay and lesbian family building. 2015. [http://uscfertility.org/gay-lesbian-familybuilding/]. Accessed 12 January 2016.

15 Golombok S, Perry B, Burston A, Murray C, Mooney-Somers J, Stevens M. Children with Lesbian Parents: a Community Study. Dev Psychol 2003;39:20-33.

16 Gartrell N, Bos H. US, National Longitudinal Lesbian Family Study. Psychological adjustment of 17-year old adolescents. Pediatrics 2010;126:28-36.

17 Rights of Women. Women's equality; lesbian parents. 2014. [http:// rightsofwomen.org.uk/about-us/herstory/our-campaigns-2/\#Lesbian]. Accessed 12 January 2016.

18 Mercer C, Tanton C, Prah P, Erens B, Sonnenberg P, Clifton S, et al. Changes in sexual attitudes and lifestyles in Britain through the life course and over time: findings from the National Surveys of Sexual Attitudes and Lifestyles (Natsal). Lancet 2013;382:1781-94.

19 Davies C. Sue Perkins describes 'bereavement' of being unable to have children. The Guardian. 2015. [www.theguardian.com/tv-andradio/2015/sep/20/sue-perkins-infertile-bereavement-children]. Accessed 12 January 2016.

20 Kelleher C. Minority stress and health: implications for Lesbian, Gay, Bisexual, Transgender, and Questioning (LGBTQ) young people. Counselling Psychol Q 2009;22:373-9.

21 Rivers I. Recollections of bullying at school and their long-term implications for lesbians, gay men, and bisexuals. Crisis 2004;25:169-75.

22 Kosciw JG, Greytak EA, Palmer NA, Boesen MJ. The 2013 National School Climate Survey. The Experiences of Lesbian, gay, Bisexual, and Transgender Youth in our Nation's Schools. The Gay, Lesbian, and Straight Education Network, 2014. [www.glsen.org/article/2013national-school-climate-survey].Accessed 12 January2016.

23 METRO Youth Chances, 2013. Survey of 16-25 Year Olds: First Reference Report. London: METRO, 2013. [www.youthchances.org/] Accessed 12 January 2016.

24 King M, Semlyen J, See Tai S, Killaspy H, Osborn D, Popelyuk D, et al. A systematic review of mental disorder, suicide, and deliberate self harm in lesbian, gay and bisexual people. BMC Psychiatry 2008;8:70. 
Hodson et al.

25 American Congress of Obstetricians and Gynaecologists. Ob-Gyns support same-sex marriage equality. 2013. [www.acog.org/AboutACOG/News-Room/News-Releases/2013/Ob-Gyns-Endorse-Same-SexMarriage-Equality]. Accessed 12 January 2016.

26 Jennings S, Mellish L, Tasker F, Lamb M, Golombok S. Why Adoption? Gay, lesbian, and hetersexual parents' reproductive experiences and reasons for adoption. Adoption Q 2014;17:20526

27 Saewyc E, Poon C, Homma Y, Skay C. The links between enacted stigma and teen pregnancy trends among gay, lesbian, and bisexual students in British Columbia. Can J Hum Sexuality 2008;17:123-39.

28 Charlton B, Corliss H, Missmer S, Rosario M, Spiegelman D, Bryn AS. Sexual orientation differences in teen pregnancy and hormonal contraceptive use: an examination across 2 generations. Am J Obstet Gynecol 2013;209:204.e1-8.

29 Lindley L, Walsemann K. Sexual orientation and risk of pregnancy among New York City high-school students. Am J Public Health 2015;105:1379-86.

30 Riskind R, Tornello S, Younger B, Patterson C. Sexual identity, partner gender, and sexual health among adolescent girls in the United States. Am J Public Health 2014;104:1957-63.

31 Tornello S, Riskind R, Patterson C. Sexual orientation and sexual and reproductive health among adolescent young women in the United States. J Adolesc Health 2014;54:160-8.

32 Agrawal R, Sharma S, Bekir J, Conway G, Bailey J, Balen AH, et al. Prevalence of polycystic ovaries and polycystic ovary syndrome in lesbian women compared with heterosexual women. Fertil Steril 2004;82:1352-7

33 Salomon M, Sylvest $R$, Hansson $H$, Andersen AN, Schmidt L. Sociodemographic characteristics and attitudes towards motherhood among single women compared with cohabiting women treated with donor semen-A Danish multicenter study. Acta Obstet Gynecol Scand 2015;94:473-81.

34 Mercer C, Bailey J, Johnson A, Erens B, Wellings K, Fenton K, et al. Women who report sex with women: national probability data on prevalence, sexual behaviours, and health outcomes. Am J Public Health 2007;97:1126-33.

35 Dibble S, Roberts S, Robertson P, Paul S. Risk factors for ovarian cancer: lesbian and heterosexual women. Oncol Nursing Forum 2002;29:E1-7.

36 Chetcuti N, Beltzer N, Methy N, Laborde C, Velter A, Bajos N, CSF Group. Preventive care's forgotten women: life course, sexuality, and sexual health among homosexually and bisexually active women in France. J Sex Res 2013;50:587-97.

37 Dibble SL, Roberts ST, Nussey B. Comparing breast cancer risk between lesbians and their heterosexual sisters. Women's Health Issues 2004;14:60-8.

38 Moegelin L, Nilsson B, Helström L. Reproductive health in lesbian and bisexual women in Sweden. Acta Obstet Gynecol Scand 2010;89:205-9.

39 Fethers K, Marks C, Mindel A, Estcourt CE. Sexually transmitted infections and risk behaviours in women who have sex with women. Sexually Transm Infect 2000;76:345-9.

40 Tarin JJ, García-Pérez MA, Cano A. Deficiencies in reporting results of lesbians and gays after donor intrauterine insemination and assisted reproductive technology treatments: a review of the first emerging studies. Reprod Biol Endocrinol 2015;13:52.

41 McManus AJ, Hunter LP, Renn $H$. Lesbian experiences and needs during childbirth: guidance for health care providers. JOGNN 2006:35:13-23.

42 Evening Standard. Lifestyle section. Meet the gayby doctor. 2010. [www.standard.co.uk/lifestyle/meet-the-gayby-doc-6534975.html]. Accessed 12 January 2016
43 Masoudian P, Nasr A, De NJ, Fung KFK, Bainbridge SA, El Demellawy D. Oocyte donation pregnancies and the risk of preeclampsia or gestational hypertension: a systematic review and meta-analysis. Am J Obstet Gynecol 2016;214:328-39

44 Hinchliffe S, Gott M, Galena E. 'I daresay I might find it embarrassing'-general practitioners perspectives on discussing sexual health issues with lesbian and gay patients. Health Social Care Commun 2004;13:345-53.

45 Westerstahl A, Segesten K, Bjorkelund C. GPs and lesbian women in the consultation: issues of awareness and knowledge. Scand J Primary Health Care 2002;20:203-6.

46 Dibley L. Experiences of lesbian parents in the UK: interactions with midwives. Evidence Based Midwifery 2009. [www.rcm.org.uk/ learning-and-career/learning-and-research/ebm-articles/experiencesof-lesbian-parents-in-the-uk-0]. Accessed 12 January 2016].

47 Borneskog C, Svanberg AS, Lampic C, Sydsjö G. Relationship quality in lesbian and heterosexual couples undergoing treatment with assisted reproduction. Hum Reprod 2012;27:779-86.

48 Borneskog C, Lampic C, Sydsjö G, Bladh M, Svanberg AS. Relationship satisfaction in lesbian and heterosexual couples before and after assisted reproduction: a longitudinal follow-up study. BMC Women's Health 2014;14:1-10.

49 Brandenburg DL, Matthews AK, Johnson TP, Hughes TL, RN \& FAAN. Breast cancer risk and screening: a comparison of lesbian and heterosexual women. Women Health 2007;45:109-30.

50 Brewster KL, Tillman KH, Jokinen-Gorden $H$. Demographic characteristics of lesbian parents in the United States. Population Res Policy Rev 2014;33:503-26.

51 Case P, Bryn Austin S, Hunter DJ, Manson JE, Malspeis S, Willett WC, et al. Sexual orientation, health risk factors, and physical functioning in the nurses' health study II. J Women's Health 2004:13:1033-47.

52 De Sutter P, Dutré T, Vanden Meerschaut F, Stuyver I, Van Maele G, Dhont M. PCOS in lesbian and heterosexual women treated with artificial donor insemination. Reprod Biomed Online 2008;17:398-402.

53 Ferrara I, Balet R, Grudzinskas JG. Intrauterine insemination with frozen donor sperm. Pregnancy outcome in relation to age and ovarian stimulation regime. Hum Reprod 2002;17:2320-4.

54 Ferrara I, Balet R, Grudzinskas JG. Intrauterine donor insemination in single women and lesbian couples; a comparative study of pregnancy rates. Hum Reprod 2000;15:621-5.

55 Fiske $E$, Weston G. Utilisation of ART in single women and lesbian couples since the 2010 change in Victorian legislation. Aust N Z J Obstet Gynaecol 2014;54:497-9.

56 Kop PAL, van Wely M, Mol BW, de Melker AA, Janssens PMW, Arends $B$, et al. Intrauterine insemination or intracervical insemination with cryopreserved donor sperm in the natural cycle: a cohort study. Hum Reprod 2015;30:1-5.

57 Nordqvist S, Sydosjö G, Lampic C, Ảkerud H, Elenis E, Skoog Svanberg A. Sexual orientation of women does not affect outcome of fertility treatment with donated sperm. Hum Reprod 2014;29:704-11.

58 Rothblum ED, Factor R. Lesbians and their Sisters as a Control Group: Demographic and Mental Health Factors. Am Psychol Soc 2001;12:63-9.

59 Solomon SE, Rothblum ED, Balsam KF. Pioneers in partnership: lesbian and gay male couples in civil unions compared with those not in civil unions and married heterosexual siblings. J Family Psychol 2004; 18:275-86

60 Valanis BG, Bowen DJ, Bassford T, Whitlock E, Charney P, Carter RA. Sexual orientation and health. Arch Fam Med 2000;9:843-5.

61 Wiik KA, Seierstad A, Noack T. Divorce in Norwegian same-sex marriages and registered partnerships: the role of children. J Marriage Family 2014;76:919-29 